\title{
Local terrain-topography and thermal-properties influence on energy and mass balance of a snow cover
}

\author{
E.E. ADAMS, A.E. SLAUGHTER, L. McKITTRICK, D.A. MILLER \\ Department of Civil Engineering, Montana State University, 205 Cobleigh Hall, Bozeman, MT 59717-3900, USA \\ E-mail: eda@ce.montana.edu
}

\begin{abstract}
Snow's interaction with the environment is an important area in environmental science, particularly as climatic conditions change. We consider the local influence at the slope or smaller scale. Near-surface properties drive the dynamic interface with the atmosphere and with surrounding terrain. While accounting for topography, complex interactions involving energy and mass transfer at the snow surface are considered, using a computer simulation (RadTherm/RT). Digital elevation maps are used to numerically fabricate terrain features and vegetation, while applying appropriate thermal properties to specified terrain types. Conduction, convection radiation and phase change (for dry snow) are considered. Particularly relevant to this study are longwave infrared and shortwave radiation, which in the model account for shadowing, multiple reflective and emissive contributions. An example of a north-facing $30^{\circ}$, snow-covered clearing bounded by trees is examined using measured meteorological conditions. Applying the same weather conditions, the model is used to examine the difference if the trees are assumed bare or covered with snow. Results indicate that, for the conditions considered, when trees are covered with snow, the open slope is cooler and the snow mass loss is less. Spatial variability across the slope is also noted. Differences are largely due to topographic radiation exchange.
\end{abstract}

\section{INTRODUCTION}

The reflective characteristics of snow are important in the atmospheric energy balance. Consequently, the areal and temporal extent is of major consequence to the global climate. The interaction of terrain and vegetation with snow is significant. Therefore, the presence of snow-covered versus snow-free terrain features surrounding and interacting with a snow-covered slope may provide feedback with respect to the retention of the slope snow cover. The global importance is well known (Armstrong and Brun, 2008). In this paper, we quantitatively consider a theoretical example as a means to examine the influence that local surroundings may have on the energy and mass balance of snow on the slope and smaller scale. We use a modeled example to demonstrate how a snow-covered slope might be affected by its surroundings with more or less snow cover in its viewshed. We consider an open slope surrounded by trees and inspect the changes that might be expected if these trees are covered or replaced by snow. Changes in snow surface morphology will also influence the energy balance. We briefly discuss the potential influence of near-surface metamorphism.

\section{Energy-balance model}

A first-principles energy-balance model, which accounts for topography and terrain type, was the basis of this analysis. Within this model, thermal properties appropriate to terrain type are assigned and topography is constructed as an assemblage of surface elements (termed facets) which overlay subsurface nodes. Hemispherical rays emanating from each facet are defined employing enclosure theory, whereby geometric view factors with respect to all other surfaces and the sky are calculated. Meteorological data are applied and a one-dimensional (1-D) energy balance is calculated for each of these facets. Conduction, convection, radiation and latent heat are accounted for in the model; however, its unique strength is the radiation component.
Taking into account topography, global position and time, insolation relative to each facet at each time-step is calculated, as are shortwave reflection and longwave radiation exchange with the sky or other terrain surfaces. All reflecting and emitting surfaces are assumed diffuse. Surface temperature, temperature profiles and surface mass fluxes are then calculated for each of these facet elements.

Radiation was selected as the primary focus of this paper because it is understood to be one of the most important parameters influencing snow morphology near the surface. In a recent study, Slaughter (2010) and Slaughter and Adams (2010) considered an energy-balance model similar to that used here, but essentially focused on an individual element of snow. Monte Carlo simulations were used to construct a sensitivity analysis, developed by Saltelli (2002), that allows the variance in the model output to be apportioned to each of the inputs, i.e. how much of the change observed in the model output is due to the changes in each of the model inputs. Inputs included both environmental parameters (e.g. albedo and shortwave radiation) and snow properties (e.g. density and thermal conductivity). The model addressed environmental input sensitivities resulting for the formation of surface hoar and radiation recrystallization, both of which are faceted forms that affect the strength and likely alter the reflective properties of snow (Kokhanovsky and Zege, 2004; Jin and others, 2008).

In general, the work performed by Slaughter (2010) and Slaughter and Adams (2010) highlights the importance of incident long- and shortwave radiation on the snow. These results indicate that the most critical energy component for the formation of surface hoar is incoming longwave radiation. Approximately $57 \%$ of variance in the model output - mass deposition onto the snow surface - was directly related to absorbed longwave radiation. When interactions with other inputs were considered, this value increased (e.g. changes in longwave radiation coupled with changes in snow density and/or wind speed). In this case, 

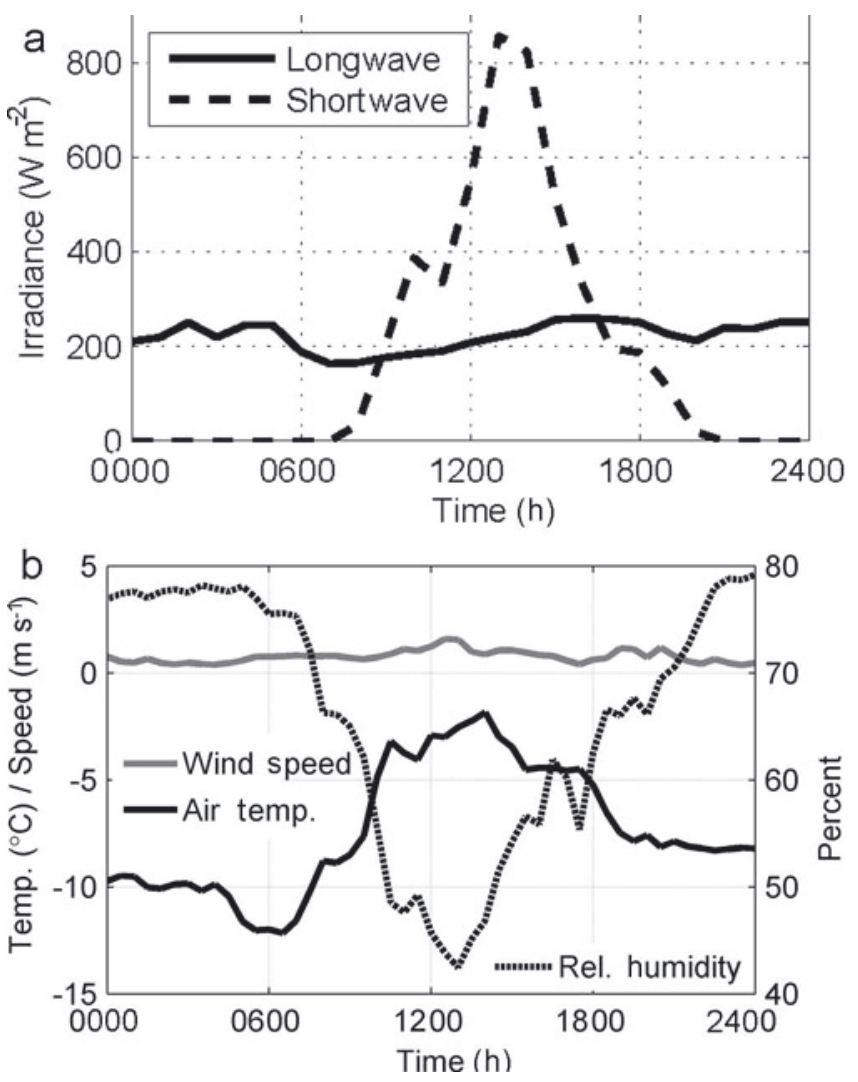

Fig. 1. Recorded (a) radiation data from a ridge above the study location and (b) air-temperature, wind-speed and relative humidity data from the north study location on 31 March 2010, which were used as input into the energy-balance model.

$\sim 74 \%$ of the output variance is in some fashion related to longwave radiation absorption.

The commercial program employed here is RadTherm/RT by ThermoAnalytics Inc. This code was originally developed to recognize the infrared/thermal signatures of vehicles based on their geometry and material composition. The same methods applied to vehicles were extended to topographically varied terrain and snow by Adams and McDowell (1991). RadTherm/RT was further extended to analyze topographically complex terrain utilizing digital elevation maps (DEMs), in collaboration between Montana State University (MSU) and ThermoAnalytics, Inc. (Adams, 1999). It was operationally tested to calculate pavement temperatures using forecast meteorological data (Adams and others, 2004) where it was found to provide reasonably accurate results (McKittrick and others, 2004). Mass flux calculations have been used to model surface hoar growth in mountainous terrain (Adams and others, 2004). A recent iteration of the model accounts for visible radiation penetration into the snowpack and consequent subsurface heating. Spatial variability of surface temperature and nearsurface temperature gradients leading to surface hoar development and radiation recrystallization has been calculated based on meteorological conditions and coupled with observations (Adams and others, 2009).

\section{STUDY LOCATION AND MODEL INPUT}

The north-facing $\sim 30^{\circ}$ slope utilized for the study is located in a generally wind-protected location below timberline at 2530 ma.s.l. $\left(45^{\circ} 14^{\prime} 52.3^{\prime \prime} \mathrm{N}, 111^{\circ} 27^{\prime} 21.8^{\prime \prime} \mathrm{W}\right)$. The site, which is located in the Yellowstone Club ski area in Montana, USA, has available meteorological data. It has been the focus of several previous studies (Cooperstein and others, 2004; McCabe and others, 2008; Slaughter and others, 2008, 2009; Adams and others, 2009). A DEM $(125 \mathrm{~m} \times 131 \mathrm{~m})$ for the site was generated from remotely sensed lidar data at a $1 \mathrm{~m}$ planar resolution. Terrain 'parts' for this site are resolved and defined as snow and coniferous trees in this model since they are the predominant winter features of this slope. Each square element was bisected to yield a triangle to more closely follow topography. These lidar data were obtained in snow-free conditions. In this study, a snow cover on the terrain was assumed, but the surface elevation was not altered.

Meteorological data for 1 day (31 March 2010) were used in the analysis in this example; these data are shown in Figure 1 . The measured input radiation values are provided from a weather station located on a ridge above the modeled slope. The location was used because of its unobstructed ridge-top view for measuring solar and sky radiation. The sun position was calculated based on geographical location and time. The DEM data allow the model to account for shadowing, multiple reflections and surface-to-surface radiation exchange based on view factors calculated for all facets. All other environmental inputs were measured at the slope. This north-facing aspect was chosen for the study since we wanted specifically to examine how the interaction with different surrounding terrain properties would influence the snow on the slope. In particular, the question was asked how might results differ if we consider the same conditions in all respects, but examine for the situation where the trees are bare, versus when they are covered with snow?

The topographic configuration of the site is such that the snow-covered slope is a consistent $30-35^{\circ}$, has a northern exposure and is surrounded by trees as indicated in Figure 2. On this date in the spring, the sun was sufficiently high (maximum solar elevation angle $49^{\circ}$ ) to clear the obstruction presented by trees on the upper (south) section of the slope, providing direct incident solar radiation to much of the slope. For the snow, measured albedo of 0.94 on this day came from slope normal upward- and downward-facing shortwave radiometers; the snow emissivity was assumed to be 0.98 . The coniferous trees were assumed to have an emissivity of 0.95 and an albedo of 0.3 .

\section{ANALYSIS}

First, we consider results averaged across the open snowcovered slope, delineated by the area without trees. For this discussion we define this area as the 'snow slope' and compare scenarios where the trees are free from snow ('snow-free trees') and where the trees are covered with snow ('snow-covered trees'). Snow-covered trees are simulated by replacing the tree thermal properties with thermal properties of fresh snow. Figure 3 displays the calculated temperature difference between the two scenarios for the average temperature of the entire snow slope and for a few selected facets. The locations of these facet elements are labeled in Figure 2. The calculations indicate that the snow on the slope for the snow-covered trees scenario is colder for the entire duration and reaches a maximum in the early afternoon. The difference at individual facets reveals this same trend; however, there is a distinction depending on position relative to the surrounding terrain features. 

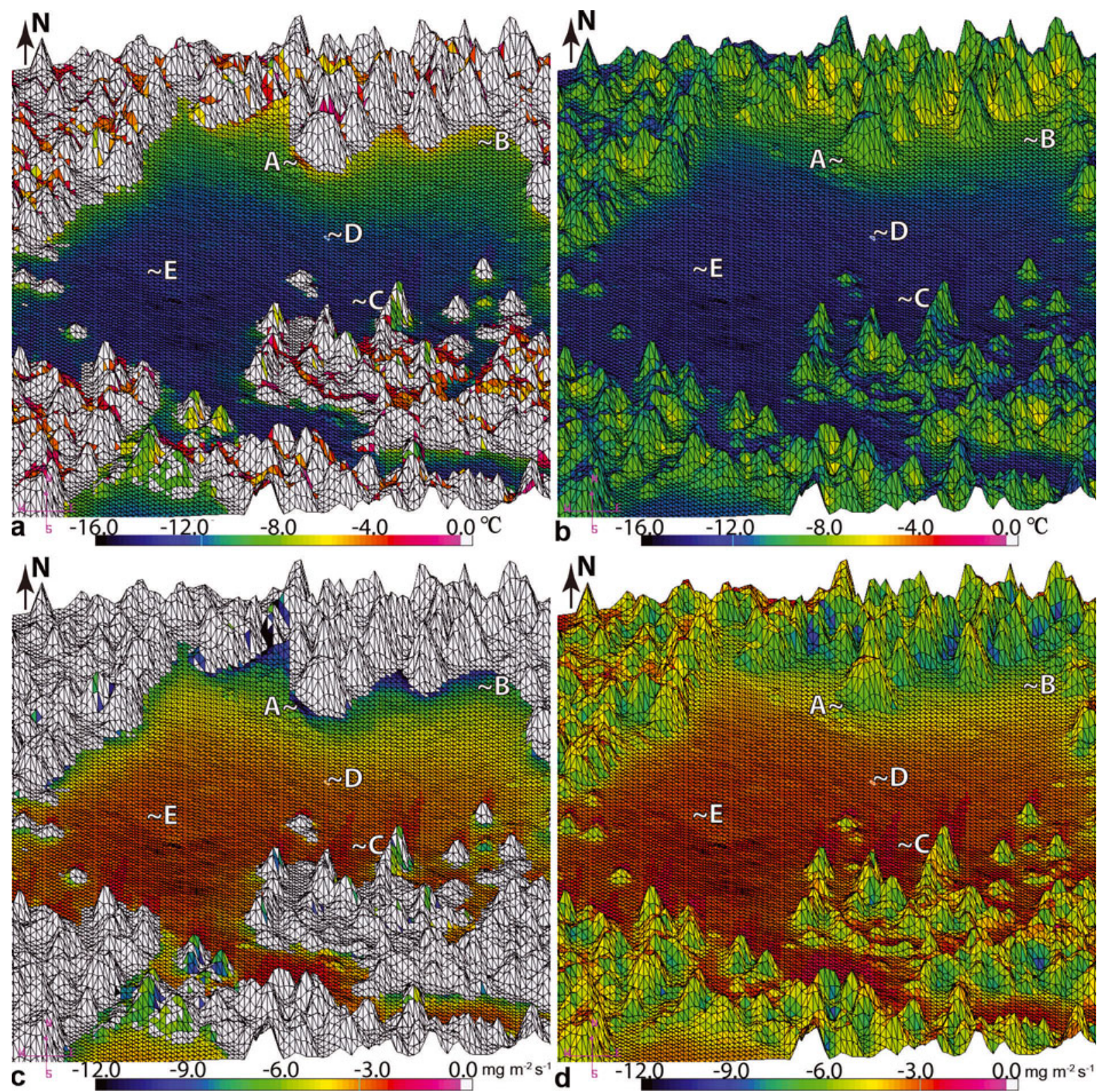

Fig. 2. Digital elevation map $(\sim 125 \mathrm{~m} \times 131 \mathrm{~m})$ demonstrating an instantaneous spatial temperature and mass flux distributions calculated at 1300 h. (a) Temperature map for the snow slope surrounded by snow-free trees; (b) temperature map for the snow slope with the snowcovered trees scenario; (c) mass flux for the snow-free trees scenario; and (d) mass flux for the snow-covered trees case. The locations of selected points are labeled.

Radiation incident on the snow slope (Fig. 4) is strongly influenced by the different materials and their topographic orientation. This is the result of direct and reflected shortwave (solar) radiation as well as longwave (infrared) radiation exchange between each snow slope facet, with its surroundings and with the sky. Figure 4 provides a time history of the radiation averaged over all snow-slope facets. Figure $4 \mathrm{~b}$ provides a measure of the energy gain due to radiation for the snow for the two scenarios. Energy is added to the snow cover by shortwave radiation (Fig. 4b). Shortwave radiation penetrates the surface, attenuating with depth. The snow surface is cooled as there is a net energy loss due to longwave radiation (Fig. 4b).

The spatial variation of the snow slope temperature and the difference in this variation between scenarios is apparent in Figure 2. This spatial variability is largely a response to the variations in the forcing radiation induced by the surrounding terrain, its properties and general topology. Clearly from
Figure 4, the shortwave incident to the snow slope is greater for the snow-covered trees condition. This increase is directly related to the higher albedo of the snow, relative to that of the trees. As shown in Figure 5, the difference at some locations is substantial. Note that at location C, there is a pronounced decrease as a result of shadowing from the trees just uphill to the south. It is also apparent that there is a marked difference for the incident longwave (infrared) for the different conditions. Here, again strongly dependent on location, the incident longwave is adding more energy in the case of the snow-free trees, resulting in generally less energy loss from the snow slope (Fig. 4b).

An extremely important aspect considered here is the mass gained or lost from the snowpack. Figure 6 displays the calculated mass flux averaged for the entire tree-free snowpack surface area of $7500 \mathrm{~m}^{2}$ for the two scenarios. Clearly there are periods of deposition (+) and periods of sublimation (-). During times of deposition, accumulation is 


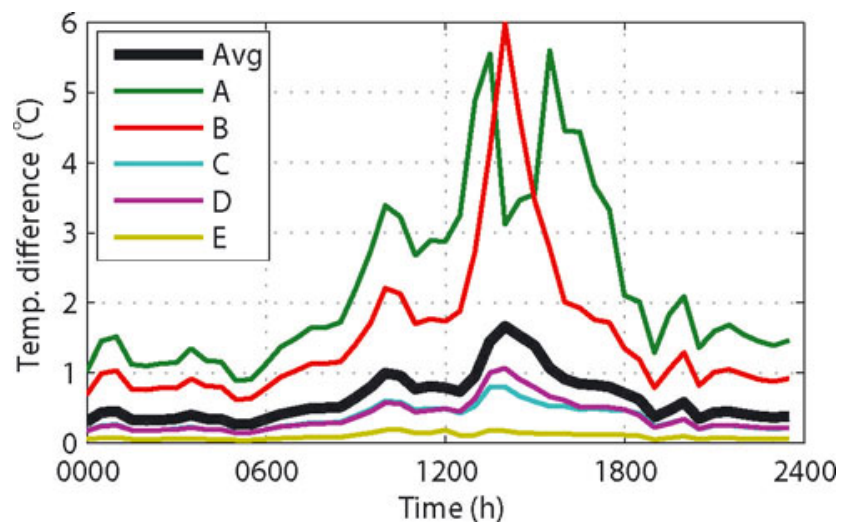

Fig. 3. Difference in calculated temperatures for the two scenarios modeled (snow-free trees minus snow-covered trees); for selected elements and for the average of all elements on the tree-free snow slope. The case with the snow-free trees indicates the snow slope is warmer everywhere. Locations of the individual facets are displayed in Figure 2.

greater for the snow-covered trees scenario, while during sublimation the rate of mass loss is less.

Integrating calculated flux values for this entire day indicates that there would be a total mass loss for both cases. Overall, the analysis yields a loss of snow for the snowcovered trees condition that is $27 \%$ less than that of the trees. Considering the individual contribution for periods of accumulation, we see that for the snow-covered trees, mass flux is $32 \%$ greater than for the snow-free trees, and for periods of sublimation the loss is $18 \%$ less than for the snowfree trees. The accumulation-to-loss ratio of mass on the slope for the snow-free trees is 0.14 and for the snowcovered trees is 0.24 .

\section{DISCUSSION}

In this numerical analysis, we examine the influence that topography and terrain thermal properties may have on snow. We consider the potential of what might be expected at the slope scale and finer in the presence or absence of adjacent snow-covered topographically complex terrain. In this study, the terrain materials considered are snow and deciduous trees. However, other materials (e.g. rocks, different vegetation or man-made structures) could be examined using appropriate properties. Of particular relevance to this study is the influence of short- and longwave radiation interactions.

The shortwave albedo of snow-free trees is lower than for snow-covered trees, which induces relatively greater heating of the trees when they are exposed to solar loading. This higher temperature, apparent in Figure 2, results in greater longwave emission from the snow-free trees to the snow on the slope. Conversely, there is less heating of the snowcovered trees due to solar loading, resulting in less incident longwave radiation to the snow on the slope. As a consequence, the higher albedo of the snow-covered trees yields greater incident shortwave to the snow slope due to the greater reflection. Particularly noteworthy to this distinction is physically where these processes are most prominent. The influence is most pronounced at the bottom, northern edge of the snow slope (Figs 2 and 5) near complex features in 'view' of the snow.
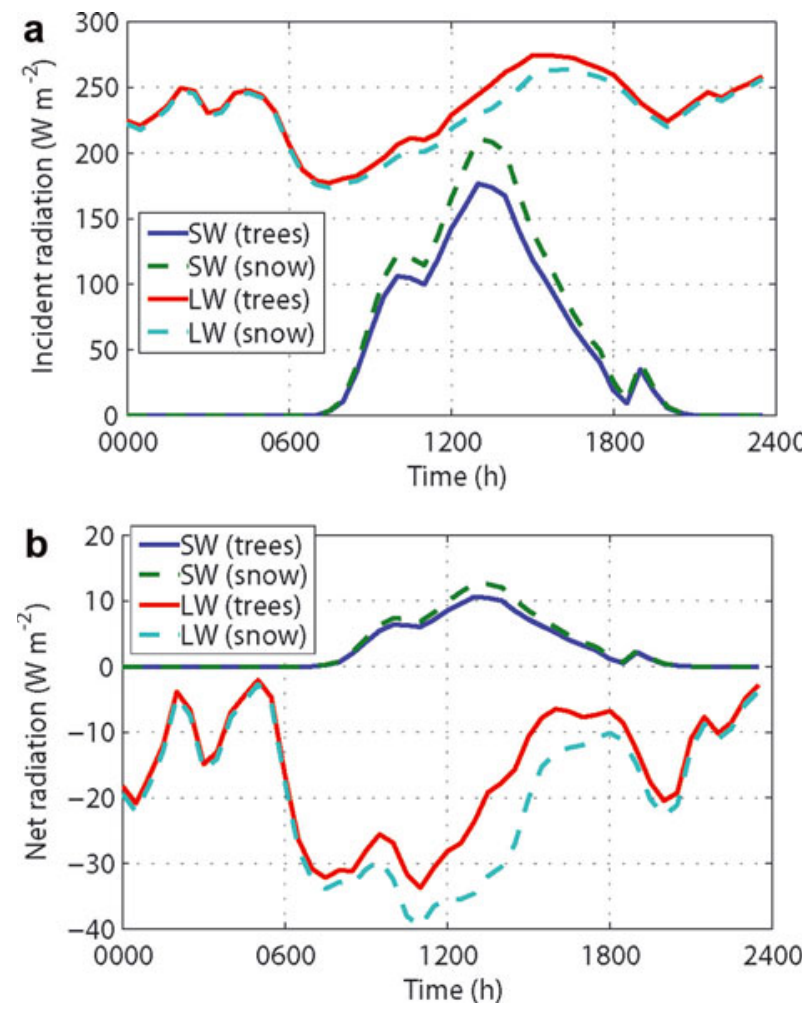

Fig. 4. The average radiation across the snow slope for (a) incident longwave (LW) and shortwave (SW) and (b) net (absorbed) solar and infrared radiation for the snow-free and snow-covered trees settings, respectively labeled as 'trees' and 'snow' in the legend.

Although direct sunlight is available to this north-facing, tree-bounded, $\sim 30^{\circ}$ open snow slope at this time of year, it is at an oblique incident angle. This oblique orientation yields a smaller facet view factor with the sun. The facet view factor for the generally vertical trees that are subjected to direct solar radiation (e.g. at the bottom northern edge of the open slope) is greater. With this and the thermal properties of the two terrain types known, the radiation exchange is calculated.

The influence of energy exchange on the snow temperature is determined, to a large degree, by its high shortwave reflectivity and near black-body emissivity. These factors are apparent in the net radiation displayed in Figure 4. Although there is significant incident shortwave to provide heating, the net gain is not large when compared to the net longwave energy loss. Also the net shortwave radiation gain for the snow is greater for the snow-covered trees than for the snowfree trees due to increased reflectivity of the snow-covered trees resulting in increased reflection to the snow slope. However, with regard to the terrain radiation exchange, the longwave net loss is still the more significant factor.

It should be noted that the longwave exchange takes place at the snow surface, while a portion of the incident shortwave will penetrate the snow to be absorbed throughout the depth, with less available with increasing depth. It is this property that can, in certain instances, have a profound influence on the near-surface snow morphology, producing a thin layer of faceted crystals at and just below the surface. While much of the incident shortwave energy may be reflected for certain snow types, the solar influence is very important. It should also be stated that the albedo of snow is variable, ranging from 0.80 to 0.95 for fresh dry snow; 0.70 
to 0.80 for old, dry snow; 0.5 to 70 for wet snow; and 0.25 to 0.8 for melting ice/snow (Armstrong and Brun, 2008). While these albedo values are useful in analyses such as this, the snow albedo is highly wavelength-dependent (Armstrong and Brun, 2008).

New snow has one of the highest albedos in the visible spectrum of any natural material, with pure snow typically absorbing $<10 \%$ of the incoming visible radiation. In the near-infrared (NIR), approximately $20-60 \%$ of the energy is absorbed depending on snow grain size. For the shortwave infrared (SWIR) and longer wavelengths, snow is essentially a black body absorbing nearly $100 \%$ of the energy (Armstrong and Brun, 2008). In the NIR, grain size is a primary variable in determining a snow-cover albedo, while the visible albedo is largely insensitive to grain size (Wiscombe and Warren, 1980; Dozier and Painter, 2004). An optically equivalent spherical grain size is normally calculated or measured when determining the NIR dependence. Since little energy penetrates the snow surface above the visible wavelengths, grain size has appropriately been used as a principal parameter to estimate the NIR albedo. With the highly active thermodynamic microstructure near the surface and the potential for surface penetration of visible radiation, rapid and dramatic changes in nearsurface morphology are frequently observed. Little consideration has been given to crystal habit in albedo effects, but there are indications that morphology may be a significant contributor to visible reflectance, particularly if considered from variable directions. Jin and others (2008) indicated that the equivalent spherical grain approach worked well when reflected energy was hemispherically averaged, but overestimated forward-reflected energy and under-predicted backscattered irradiances. They argue that reflected directional properties of snow depend on snow particle shapes. The topographic influences discussed here may result in altered snow grain morphologies that, in turn, influence snow slope radiation exchanges. This interaction provides a potential environmental feedback mechanism as altered geometric parameters give rise to altered radiation exchanges.

Although no physical observation of the snow was made on this day, faceted surface hoar crystals likely developed during the night. This conclusion is based on a separate study carried out on this same slope when widespread $5 \mathrm{~mm}$ surface hoar crystals were observed (Adams and others, 2009). Applying the RadTherm/RT model to the meteorological conditions in that instance, mass flux values similar to those calculated here were observed. In the present study, the onset of melt was also calculated at a few locations on the slope, which would indicate a change in morphology toward larger, more rounded grains. This trend is relevant since changes in grain size and possibly shape will influence the snow albedo and consequently play an evolving role in the energy and mass balance. This evolution is an area of research that is relevant to environmental snow science.

Furthermore, the resulting temperature differences displayed in Figure 3 are also influenced by the convective atmospheric exchange and conduction in the snowpack, which are governed in part by the temperature of the snow surface itself. Phase change also contributes to the resulting snow temperature. We note that phase change of the snow following the onset of melt is not adequately handled in this model due to the complex interactions that result from phase change in the three-phase granular material.
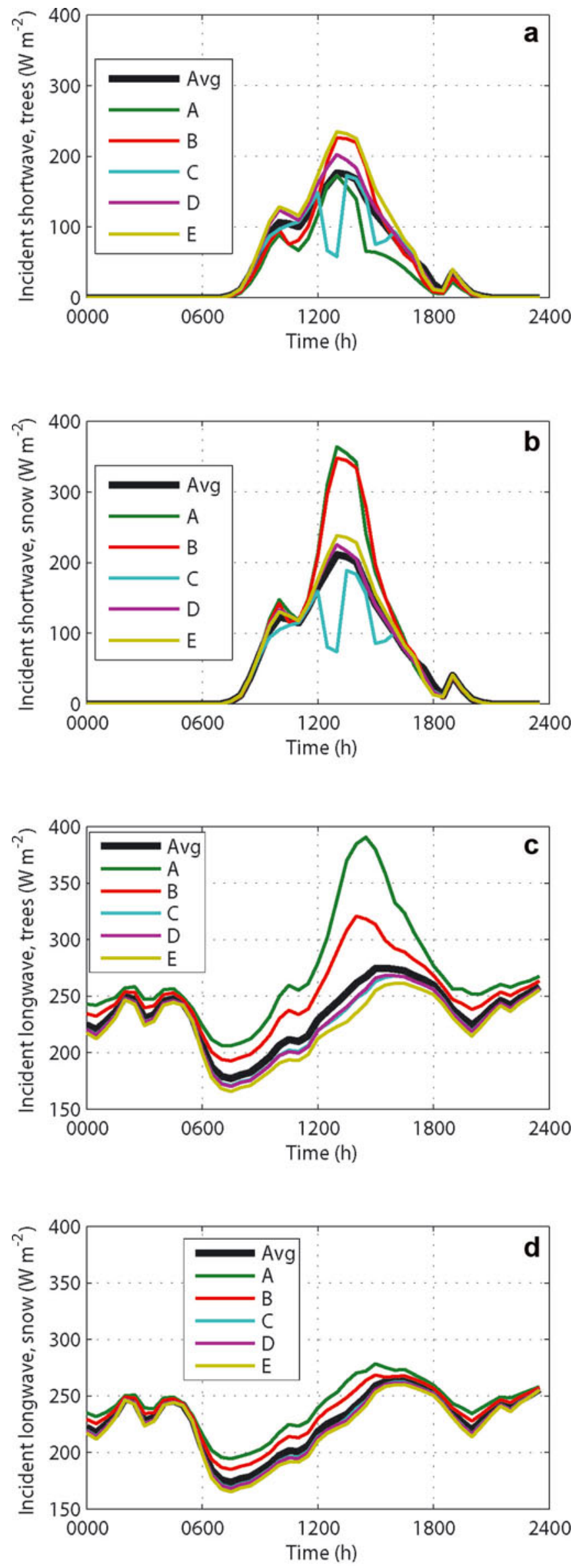

Fig. 5. Selected facets and the average for the snow slope for the calculated incident shortwave radiation for (a) snow-free trees and (b) snow-covered trees. The calculated incident longwave radiation for (c) snow-free trees and (d) snow-covered trees. 


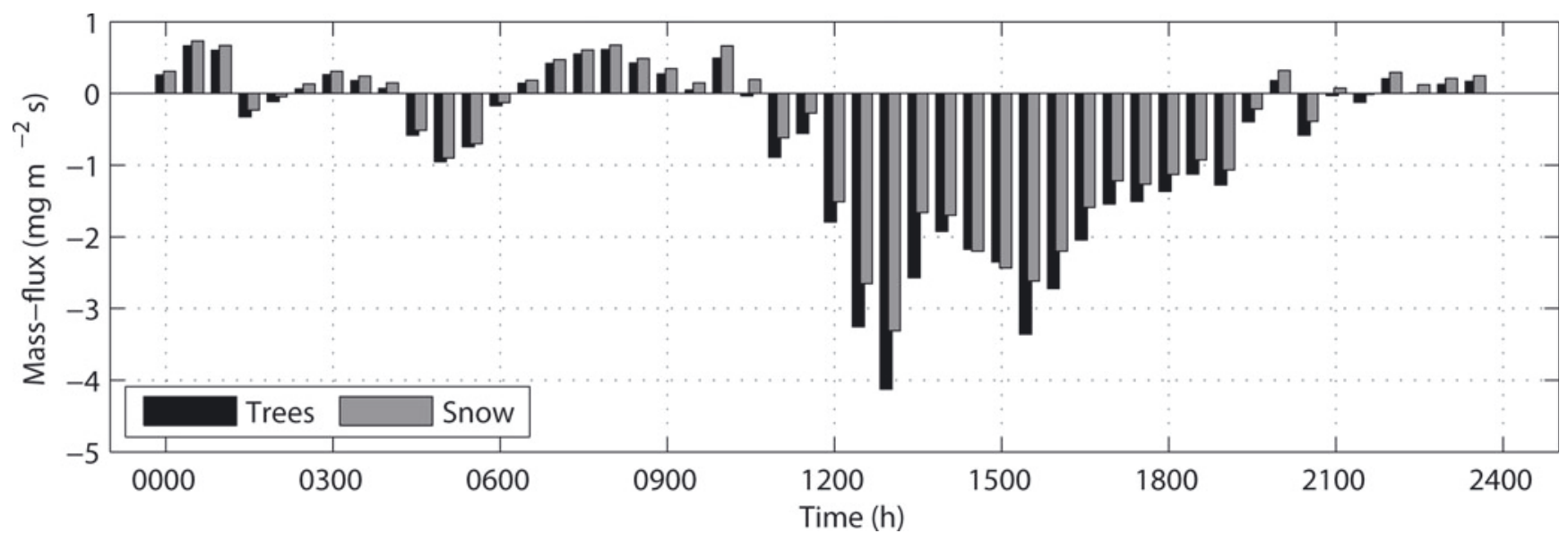

Fig. 6. The rate of mass flux averaged for the entire snowpack for the snow-covered trees (snow) and the snow-free trees (trees) scenarios. Positive values indicate mass deposition onto the snow slope, and negative values indicate sublimation.

\section{CONCLUSIONS}

Our interest in this study is to examine how differences in snow coverage, whether the result of annual variations or longer-term climate deviations, may influence a snow cover at the local scale. At the global scale, feedback to the atmosphere that accompanies the areal coverage of the snow generally implies that a reduction in extent will result in atmospheric warming. Consequently, adjusting the areal extent of snow for a given annual point in time can have important climatic ramifications. We approach this concept from a local scale, i.e. at the slope scale or smaller, rather than the larger global or regional scale. This smaller size consideration when integrated to a larger area, naturally, contributes and adds detail to the bigger issue. We do not attempt in this study to quantitatively scale these results up to the global scale.

Changes in precipitation patterns may dictate modifications of the seasonal extent of the snow cover, so that portions of the local landscape will have different distributions. In our analysis, we examined how different portions of the landscape with material-specific thermal properties would interrelate. We examined a specific case of snowfree trees and snow-covered trees and how they would interact with a specific snow-covered slope at a particular time. However, conclusions and analysis techniques from this case study are applicable to other materials such as rock and to different topographies. For the scale we examined, a primary consideration of importance is the inter-surface and the surface-to-atmosphere and surface-to-sun view factors. If we had considered flat terrain with little or no inter-surface view factor association, then the influence of different thermal properties for different parts of this terrain would have little influence. This does not imply that less topographically complex terrain (which also has a mix of snowcovered and non-snow-covered terrain) is not important on a larger or global scale as an influential factor in climate analysis. Nor does it imply that there are not important considerations at the local scale for snow with another material at the lateral interface, such as patches of bare ground interspersed with snow, where for example transverse conduction might be important.

The influence of snow-covered versus non-covered topographically complex terrain has a significant spatially varied influence on both the energy and mass balance at the local slope and smaller scale. For conditions modeled in the example case presented for dry snow, when terrain (i.e. trees) was snow-covered, the adjacent snow-covered slope always remained cooler and had less mass loss. Examination of these important balance considerations at the local scale accounting for topography and terrain properties is relevant to a comprehensive understanding at the global scale. Additional investigation is warranted.

It is important to examine variation at the small scale as well as at the global and regional scales. A robust evaluation governing environmental variation important at these smaller scales and modeling efforts such as this could be helpful to a deeper understanding of this complex system. It will also be important to continue to examine more completely the changes that snow surface morphology makes in the feedback relative to snow retention and the resultant influence on the global environment.

\section{ACKNOWLEDGEMENTS}

This work was funded by US National Science Foundation (NSF) grant EAR-0635977 and the NSF Graduate Teaching Fellows in K-12 Education Program, with contributions from the 2000 International Snow Science Workshop fund and the American Avalanche Association.

\section{REFERENCES}

Adams, E.E. 1999. Proof of concept for predication of pavement temperature: a tactical decision aid for highway safety. Helena, MT, Montana Department of Transportation. Federal Highway Administration. (Final Report FHWA/MT-99-003/8117-6.)

Adams, E.E. and S.A. McDowell. 1991. Thermal model for snow on three-dimensional terrain. In Tominaga, M., ed. Proceedings of Japan-U.S. Symposium on Snow Avalanche, Landslide, Debris Flow Prediction and Control. Tsukuba, Science and Technology Agency of Japan, 75-84.

Adams, E.E., P. Gauer, L.R. McKittrick and A.R. Curran. 2004. A first principles pavement thermal model for topographically complex terrain. Transport. Res. Circ. E-C063, 422-432.

Adams, E.E. and 11 others. 2009. Modeling variation of surface hoar and radiation recrystallization across a slope. In Schweizer, J. and C. Gansner, eds. Proceedings of the International Snow Science Workshop, 27 September-2 October 
2009, Davos, Switzerland. Birmensdorf, Swiss Federal Institute for Forest, Snow and Landscape Research, 97-101.

Armstrong, R.L. and E. Brun, eds. 2008. Snow and climate: physical processes, surface energy exchange and modelling. Cambridge, etc., Cambridge University Press.

Cooperstein, M., K.W. Birkeland and K. Hansen. 2004. The effects of slope aspect on the formation of surface hoar and diurnally recrystallized near-surface faceted crystals: implications for avalanche forecasting. In Elder, K., ed. Proceedings of the International Snow Science Workshop, 19-24 September 2004, Jackson Hole, Wyoming. Jackson Hole, WY, International Snow Science Workshop, 83-93.

Dozier, J. and T.H. Painter. 2004. Multispectral and hyperspectral remote sensing of alpine snow properties. Annu. Rev. Earth Planet. Sci., 32, 465-494.

Jin, Z., T.P. Charlock, P. Yang, Y. Xie and W. Miller. 2008. Snow optical properties for different particle shapes with application to snow grain size retrieval and MODIS/CERES radiance comparison over Antarctica. Remote Sens. Environ., 112(9), 3563-3581.

Kokhanovsky, A.A. and E.P. Zege. 2004. Scattering optics of snow. Appl. Opt., 43(7), 1589-1602.

McCabe, D., and 8 others. 2008. Near surface faceting on south aspect in southwest Montana. In Campbell, C. and S. Conger, eds. Proceedings of the International Snow Science Workshop,
21-27 September 2008, Whistler, British Columbia, Canada. International Snow Science Workshop, 147-154.

McKittrick, L.R., E.E. Adams, P. Gauer, J. Mewes and A.R. Curran. 2004. Forecasting terrain dependent weather conditions: details of a model-chain sequence. Transport. Res. Circ. E-C063, 95-108.

Saltelli, A. 2002. Making best use of model evaluations to compute sensitivity indices. Comput. Phys. Comm., 145(2), 280-297.

Slaughter, A. 2010. Numerical analysis of conditions necessary for near-surface snow metamorphism. (PhD thesis, Montana State University.)

Slaughter, A. and E.E. Adams. 2010. Field and analytical examination of near-surface faucets. In Osterhuber, R.,, eds. Proceedings of the International Snow Science Workshop, 17-22 October 2010, Lake Tahoe, CA. International Snow Science Workshop, 31-39.

Slaughter, A.E. and 8 others. 2008. Laboratory simulations of radiation-recrystallization events in Southwest Montana. In Campbell, C. and S. Conger, eds. Proceedings of the International Snow Science Workshop, 21-27 September 2008, Whistler, British Columbia, Canada. International Snow Science Workshop, 139-146.

Slaughter, A., and 8 others. 2009. An investigation of radiationrecrystallization coupling laboratory and field studies. Cold Reg. Sci. Technol., 59(2-3), 126-132.

Wiscombe, W.J. and S.G. Warren. 1980. A model for the spectral albedo of snow. I. Pure snow. J. Atmos. Sci., 37(12), 2712-2733. 